\title{
Perancangan Sistem Pengendali Jarak Jauh Berbasis Mikrokontroler Pada Rumah Cerdas
}

\author{
Lewi $^{1^{*}}$ dan Abdul Rahman ${ }^{2}$ \\ 1,2 Jurusan Teknik Mesin, Politeknik Negeri Ujung Pandang, Makassar 90245, Indonesia \\ *elw_pnup@yahoo.com
}

\begin{abstract}
In the construction of a house, the model or design is often the main priority, while the electrical installation is not given much attention. As a result, the need for electrical energy is increasing rapidly. In addition, the increasing demand for electrical energy is also due to a lack of supervision and control over household electricity consumption. A simple solution to save energy while facilitating monitoring of electrical energy use is a system that integrated with various devices in the house. This system is also necessary because it can be controlled by the owner of the house remotely, namely by short message (SMS). This control system is controlled by an Arduino microcontroller as a control center connected to a device to turn on the lights. The microcontroller is connected to the GSM Shield which functions as a device that receives messages as short as those sent by the home owner. The contents of the message received by the GSM Shield will be read by the microcontroller and if the contents of the message are correct, the microcontroller can give instructions to the device to turn on the light.
\end{abstract}

Keywords: Arduino; Microcontroller; Smart House; SMS

\begin{abstract}
Abstrak: Dalam pembangunan rumah sering kali yang menjadi prioritas utama adalah model atau desainnya, sedangkan instalasi listriknya kurang diperhatikan. Akibatnya, kebutuhan energy listrik meningkat dengan pesat. Selain itu, meningkatnya kebutuhan energy listrik juga disebabkan oleh kurangnya pengawasan serta pengontrolan pemakaian energy listrik rumah tangga. Salah satu solusi sederhana menghemat energi sekaligus memudahkan monitoring penggunaan energi listrik adalah diperlukan suatu sistem yang terintegrasi dengan berbagai perangkat yang terdapat dalam rumah. Sistem ini juga perlu karena dapat dikontrol oleh pemiliki rumah dari jarak jauh yaitu dengan pesan singkat (SMS). Sistem pengendali ini dikontrol oleh suatu mikrokontroler arduino sebagai pusat kendali yang terhubung dengan perangkat untuk menyalakan lampu. Selain itu mikrokontroler ini terhubung dengan GSM Shield yang berfungsi sebagai perangkat yang menerima pesan seingkat yang dikirimkan oleh pemilik rumah. Isi pesan yang diterima oleh GSM Shield akan dibaca oleh mikrokontroler dan jika isi pesan tersebut tepat maka mikrokontroler dapat member instruksi pada perangkat untuk menyalakan lampu.
\end{abstract}

Kata kunci : Arduino; Mikrokontroler; Rumah Cerdas; SMS.

\section{PENDAhULUAN}

Penghematan energi listrik dewasa ini kurang diterapkan pada kehidupan sehari-hari, pasalnya banyak konsumen yang menggunakan peralatan elektronik dengan mengonsumsi listrik secara berlebihan. Salah satu masalah yang sering terjadi yaitu konsumen lupa untuk mematikan peralatan elektronik saat meninggalkan rumah dalam keadaan sedang menggunakan daya listrik. Sehingga listrik yang digunakan kurang bermanfaat dan masalah tersebut merupakan salah satu pemborosan energi listrik.

Ketidaknyamanan timbul ketika rumah sedang ditinggalkan namun ditengah perjalanan ternyata konsumen lupa belum mematikan peralatan elektronik yang terhubung dengan peralatan listrik, salah satunya yaitu stop kontak, sehingga efeknya timbul kekhawatiran terhadap konsumen akan terjadinya arus hubung singkat, dan biaya untuk membayar tagihan listrik semakin tinggi dan timbul kekhawatiran lainnya. Hal tersebut menjadi salah satu kendala bagi para pengguna listrik dimana konsumen tidak dapat mengontrol peralatan listrik dari jarak jauh dan yang bisa konsumen lakukan hanyalah kembali ke rumah untuk mematikan peralatan listrik tersebut. 
Adapun pengendali perangkat listrik pada rumah secara otomatis yang sering disebut Rumah Cerdas (Smart Home) dengan memanfaatkan suatu alat elektronika yaitu mikrokontroler. Mikrokontroler digunakan sebagai perangkat pendukung untuk kendali arus listrik, sebagai contoh sistem kendali rumah dengan SMS (Short Message Service) melalui mobile phone sebagai sistem kendali jarak jauh secara otomatis.

\section{A. Definisi Rumah Cerdas}

Rumah cerdas didefinisikan sebagai sistem yang digunakan untuk mengintegrasikan berbagai sistem yang umumnya terdapat dalam suatu rumah (bangunan). Sebuah konsep di mana perangkatperangkat yang digunakan di dalamnya dioperasikan secara otomatis dalam sebuah sistem otomasi rumah. Sistem rumah cerdas ini sudah mendukung dan membantu pemilik rumah agar dapat mengontrol peralatan listrik dari jarak jauh dengan bantuan mikrokontroler yang telah dipaket menjadi development board Arduino Duemilanove sebagai pengendali utama.

Dengan adanya teknologi rumah cerdas diharapkan dapat membantu para pengguna energi listrik dalam hal para pelanggan PLN untuk mengontrol peralatan listrik sehingga energi listrik rumah tangga dapat digunakan seefisien mungkin.

\section{B. Pemakaian Energi Listrik Rumah Tangga}

Dengan menghitung energi listrik maka dapat digunakan persamaan sebagai berikut:

Konsumsi energi/Hari = daya alat listrik (Watt) $\mathrm{x}$ lama pemakaian/Hari (jam)

Untuk menghitung konsumsi energi listrik dalam satu tahun maka dapat menggunakan persamaan

Konsumsi energi/Tahun $=$ Konsumsi energi/Hari x 365 hari

Untuk mengetahui konsumsi energi listrik rumah yang menggunakan sistem kontrol perangkat listrik dibandingkan dengan rumah yang tidak menggunakan sistem kontrol perangkat listrik, maka digunakan persamaan sebagai berikut.

Persentase penghematan $=\frac{\begin{array}{c}\text { Konsumsi energi } \\ \text { tanpa sistem } \text { kontrol }\end{array}-\begin{array}{c}\text { Konsumsi energi } \\ \text { dengan sistem kontrol }\end{array}}{\text { Konsumsi energi }} \times 100 \%$

\section{Mikrokontroler}

Mikrokontroler adalah suatu terobosan teknologi mikrokontroler dan mikrokomputer, hadir memenuhi kebutuhan pasar (market need) dan teknologi baru.

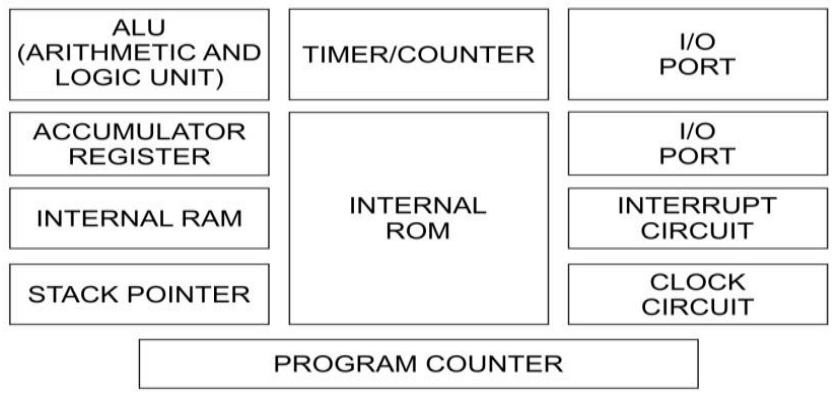

Gambar 1. Diagram blok mikrokontroler umum

\section{Mikrokontroler Arduino Uno}

Arduino Uno adalah sebuah board mikrokontroler yang berbasis pada mikrokontroler ATmega328. Suatu mikrokontroler bekerja dengan mengeksekusi perintah-perintah dalam suatu program yang diunggah ke dalam board. Arduino Uno memiliki 14 buah pin yang dapat difungsikan sebagai input/output digital, sehingga dapat dihubungkan dengan perangkat input seperti sensor untuk 
membaca kondisi dalam suatu radius tertentu, selain itu juga dapat dihubungkan dengan perangkat output lain seperti motor DC dan lampu LED.

\section{E. GSM Shield}

GSM shield adalah salah satu perangkat atau modul yang dapat dihubungkan dengan Arduino. GSM shield merupakan perangkat yang memungkinkan untuk melakukan pengontrolan perangkat output lain yang terhubung dengan Arduino melalui internet dengan menggunakan jaringan GPRS. Jaringan GPRS ini dapat digunakan sebagai pengirim/penerima pesan singkat (sms) atau panggilan telepon, selain itu shield ini juga dapat berkomunikasi dengan board Arduino dengan menggunakan AT command.

\section{F. Relay}

Relay adalah elektrikal switch yang memiliki dua kondisi, yaitu $O N$ dan $O F F$ (terbuka dan tertutup), dan dikontrol dengan rangkaian lainnya. Relay adalah komponen elektronika berupa saklar elektronik yang digerakkan oleh arus listrik.

\section{G. Short Message Service (SMS)}

Short Message Service atau dikenal dengan SMS adalah layanan seluler yang digunakan untuk mengirim dan menerima pesan singkat melalui piranti ponsel.

\section{H. Perkembangan Penelitian Sebelumnya}

Umumnya sistem kendali rumah cerdas ini digunakan untuk mengontrol penyalaan lampu di dalam rumah [1-2], dan terdapat penelitian yang menambahkan juga untuk mengontrol perangkat elektronik [3-5], perkembangan lainnya juga untuk mengontrol sistem pendingin ruangan (AC) [4-7], atau pendingin ruangan berupa kipas [8], perkembangan lainnya juga level air pada bak penampungan air (tandon) [7, 9], penelitian lainnya adalah dengan menambahkan sistem kendali pompa untuk menyiram tanaman [9-10], terdapat pula penambahan untuk mendeteksi keberadaan orang tak dikenal dalam rumah [7, 10-11], untuk mencegah bahaya kebakaran ditambahkan pula sistem kendali untuk mendeteksi kebocoran gas [7], terdapat pula penelitian yang menambahkan sistem kendali motor untuk menutup dan menutup pagar rumah [12].

Terkadang manusia juga lupa mengunci rumah ketika keluar rumah dan membutuhkan waktu lama untuk kembali kerumah sehingga dikembangkan sistem kendali rumah cerdas yang dapat menutup dan membuka kunci pintu rumah [8, 13]. Terdapat pula penelitian yang bukan hanya mengendalikan perangkat listrik AC tetapi juga perangkat listrik DC [14].

\section{METODE PENELITIAN}

A. Waktu dan Tempat Penelitian

Penelitian dilaksanakan di Kampus Politeknik Negeri Ujung Pandang, yang dilaksanakan pada bulan Februari sampai September 2015.

\section{B. Metode Analisis Data}




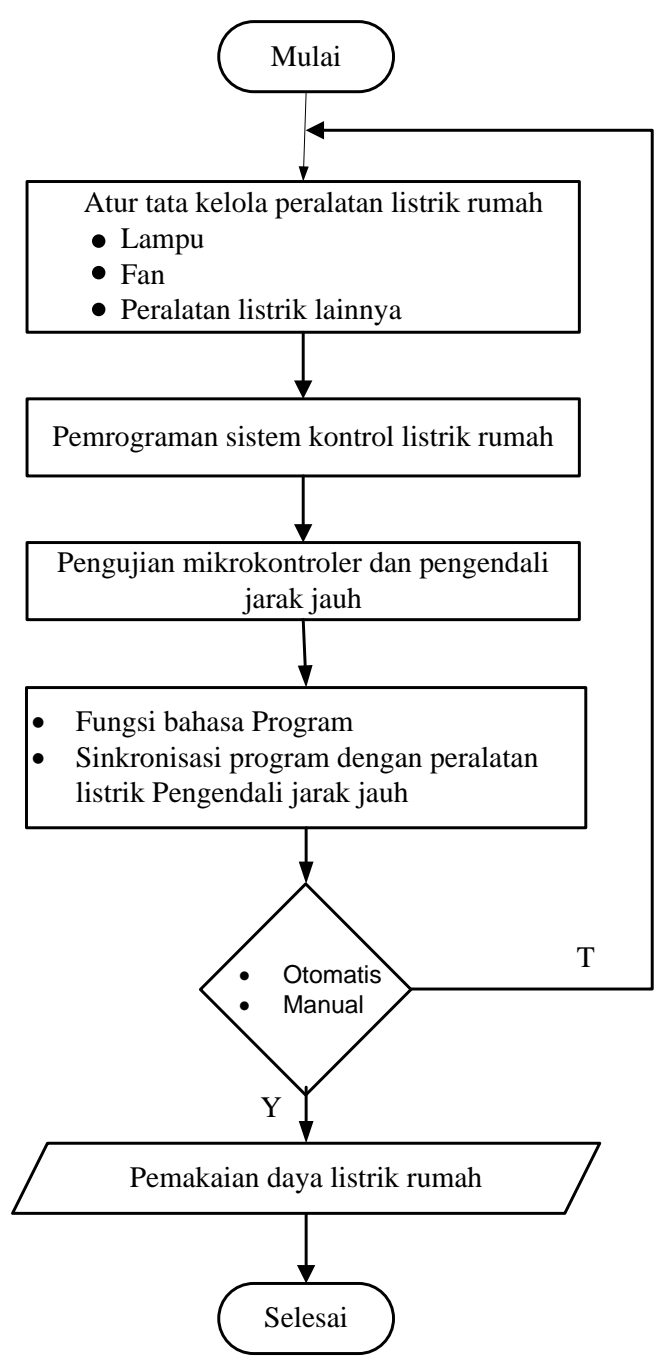

Gambar 2. Diagram Alir Penelitian

III. HASIL DAN PEMBAHASAN (Font 11, capslock)

A. Data Hasil Pengujian

Tabel 1. Data Hasil Pengujian

\begin{tabular}{|c|c|c|c|c|c|c|c|c|c|c|c|c|}
\hline \multirow{3}{*}{ No } & \multirow{3}{*}{ Beban } & \multirow{3}{*}{$\begin{array}{c}\text { Daya } \\
\text { (W) }\end{array}$} & \multirow{2}{*}{\multicolumn{2}{|c|}{ Waktu Operasi }} & \multicolumn{7}{|c|}{ Rugi Daya (per jam) [W] } & \multirow{3}{*}{$\begin{array}{c}\text { Hemat } \\
(\%)\end{array}$} \\
\hline & & & & & $\begin{array}{l}\text { Dgn Sist } \\
\text { Kontrol }\end{array}$ & \multicolumn{6}{|c|}{ Tanpa Sistem Kontrol } & \\
\hline & & & I & II & 1 & 1 & 2 & 3 & 4 & 5 & 6 & \\
\hline 1 & Lampu teras & 10 & $\begin{array}{l}17.30- \\
05.30\end{array}$ & - & 10 & 10 & 20 & 30 & 40 & 50 & 60 & 41,67 \\
\hline 2 & $\begin{array}{l}\text { Lampu ruang } \\
\text { tamu }\end{array}$ & 20 & $\begin{array}{l}17.30- \\
22.30\end{array}$ & $\begin{array}{l}05.00- \\
06.00\end{array}$ & 20 & 20 & 40 & 60 & 80 & 100 & 120 & 83,33 \\
\hline 3 & $\begin{array}{l}\text { Lampu ruang } \\
\text { keluarga }\end{array}$ & 10 & $\begin{array}{l}17.30- \\
23.30\end{array}$ & - & 10 & 10 & 20 & 30 & 40 & 50 & 60 & 83,33 \\
\hline 4 & $\begin{array}{l}\text { Lampu ruang } \\
\text { makan }\end{array}$ & 10 & $\begin{array}{l}17.30- \\
22.30\end{array}$ & $\begin{array}{c}06.00- \\
07.00\end{array}$ & 10 & 10 & 20 & 30 & 40 & 50 & 60 & 83,33 \\
\hline 5 & $\begin{array}{l}\text { Lampu kamar } \\
1\end{array}$ & 10 & $\begin{array}{l}17.30- \\
22.30\end{array}$ & $\begin{array}{c}05.00- \\
06.00\end{array}$ & 10 & 10 & 20 & 30 & 40 & 50 & 60 & 83,33 \\
\hline
\end{tabular}


255 Lewi, Abdul Rahman. Perancangan Sistem Pengendali Jarak Jauh Berbasis Mikrokontroler Pada Rumah Cerdas

\begin{tabular}{|c|l|c|c|c|c|c|c|c|c|c|c|c|}
\hline 6 & $\begin{array}{l}\text { Lampu kamar } \\
2\end{array}$ & 10 & $\begin{array}{c}17.30- \\
22.30\end{array}$ & $\begin{array}{c}05.00- \\
06.00\end{array}$ & 10 & 10 & 20 & 30 & 40 & 50 & 60 & 83,33 \\
\hline 7 & $\begin{array}{l}\text { Lampu kamar } \\
\text { mandi }\end{array}$ & 10 & $\begin{array}{c}17.30- \\
05.30\end{array}$ & - & 10 & 10 & 20 & 30 & 40 & 50 & 60 & 41,67 \\
\hline 8 & Fan kamar 1 & 45 & $\begin{array}{c}13.00- \\
15.00\end{array}$ & $\begin{array}{c}22.00- \\
05.00\end{array}$ & 45 & 45 & 90 & 135 & 180 & 225 & 270 & 50,56 \\
\hline 9 & $\begin{array}{l}\text { Fan ruang } \\
\text { makan }\end{array}$ & 45 & $\begin{array}{c}12.00- \\
14.00\end{array}$ & $\begin{array}{c}18.00- \\
20.00\end{array}$ & 45 & 45 & 90 & 135 & 180 & 225 & 270 & 50,56 \\
\hline 10 & Fan kamar 2 & 45 & $\begin{array}{c}13.00- \\
15.00\end{array}$ & $\begin{array}{c}22.00- \\
05.00\end{array}$ & 45 & 45 & 90 & 135 & 180 & 225 & 270 & 50,56 \\
\hline
\end{tabular}

\section{B. Pembahasan}

Pada tabel di atas diasumsikan pemilik rumah berangkat kerja atau sekolah pada pukul 07.00 dan lupa mematikan lampu, sedangkan pemilik rumah akan pulang ke rumah pada pukul 13.00. Sehingga dapat menyebabkan rugi daya selama 6 jam.

Dengan mengatur sistem kontrol dengan mode sms otomatis maka dapat di atur pada jam berapa pemilik rumah hendak mengecek status lampu dan peralatan listrik lainnya yang sedang aktif. Pada kasus ini diasumsikan pemilik rumah berangkat kerja atau sekolah pada pukul 07.00 dan mode sms otomatis aktif pada pukul 08.00. Jadi dengan menggunakan sistem kontrol dapat mengurangi rugi daya listrik selama satu jam.

\section{KESIMPULAN}

Dari hasil dan pembahasan pada sistem pengendali listrik rumah cerdas berbasis mikrokontroler maka dapat ditarik kesimpulan sebagai berikut:

a. Peralatan listrik rumah dapat dikontrol melalui pengujian mode manual dan pengujian mode otomatis. Mode otomatis yang telah terinstal di handphone merupakan sistem kontrol perangkat listrik dengan menggunakan aplikasi SMS auto-sender.

b. Penggunaan energi pada peralatan listrik rumah yang menggunakan sistem kontrol ketika lupa mematikan satu jam rugi daya yang didapatkan 10 Watt.

c. Penghematan energi listrik rumah tangga dengan menggunakan sistem kontrol dapat dihemat selama 1 jam dari kemungkinan rugi daya selama 6 jam.

\section{DAFTAR PUSTAKA}

[1] Wahyu Andrianto. Sistem Pengontrolan Lampu Menggunakan Arduino Berbasis Android. Diss. Universitas Islam Majapahit Mojokerto, 2019.

[2] Adi, Barep, dan Amalia Herlina. "Smart Home With Smart Control, Berbasis Bluetooth Mikrokontroller." JEECOM: Journal of Electrical Engineering and Computer 1.1 (2019).

[3] Fahmi, Ari, Aidi Finawan, dan Muhaimin Muhaimin. "Rancang Bangun Sistem Pengendali Rumah Cerdas Dengan Informasi Umpan Balik Berbasis Internet Of Things." Jurnal Tektro 3.1 (2019).

[4] Fiqri, Sultan. "Rancang Bangun Sistem Kendali Rumah Jarak Jauh Menggunakan Telepon Selular Android." Jurnal Teknik Elektro Universitas Tanjungpura 2.1 (2014).

[5] Agung, Pangestu, et al. "Sistem Rumah Cerdas Berbais Internet Of Things Dengan Mikrokontroler Nodemcu Dan Aplikasi Telegram." Jurnal Teknik dan Sistem Komputer 1.1 (2020): 8-14.

[6] Apollo, Apollo, Marhatang Marhatang, dan Abdul Rahman. "Rancang Bangun Sistim Kendali Rumah Cerdas." Jurnal Teknologi Elekterika 14.2 (2017): 163-173. 
[7] Rahayu, Endang Sri, dan Romi Achmad Mukthi Nurdin. "Perancangan Smart Home Untuk Pengendalian Peralatan Elektronik Dan Pemantauan Keamanan Rumah Berbasis Internet Of Things." Jurnal Teknologi 6.2 (2019): 136-148.

[8] Rachman, Dhenny, Moh Noor Al Azam, dan Benediktus Anindito. "Sistem Pemantau \& Pengendalian Rumah Cerdas Menggunakan Infrastuktur Internet Messaging." J. Ilm. Link 26.1 (2017): 34 .

[9] Umam, Busro Akramul, dan Yuri Efenie. "Sistem Rumah Cerdas Berbasis Internet of Things." Energy 9.2 (2019).

[10] Wahyudi, Agus. Rancang bangun rumah cerdas berbasis mikrokontroler AT89S51. Diss. Department of Physics, Diponegoro University, 2008.

[11] Fachruzzaman, Rizki Imanda. Sistem Kendali Lampu dan Keamanan Rumah Cerdas Berbasis Mikrokontroler Arduino. Diss. Universitas Islam Indonesia, 2014.

[12] Hannifannisa, Hannifannisa, dan Hastuti Hastuti. "Rancang Bangun Sistem Kendali Smart Home Berbasis Programmable Logic Controller." JTEV (Jurnal Teknik Elektro dan Vokasional) 6.2 (2020): 375-382.

[13] Muharam, Mumuh, Melda Latif, dan Mahendri Saputra. "Sistem Kendali Jarak Jauh Berbasis Web untuk Sistem Rumah Pintar." Jurnal Nasional Teknik Elektro 7.3 (2018): 203-208.

[14] Desmira, Desmira, et al. "Implementasi Prototype Sistem Kendali Kunci Pintu Dengan Smartphone Android Berbasis Microcontroller Avr Atmega 328 Dan Fuzzy Logic." Prosisko: Jurnal Pengembangan Riset dan Observasi Sistem Komputer 2.1 (2015). 